Review

\title{
Initiatives to Improve the Quality of Life of HIV Positive Diagnosed Subjects: A Review of Diagnosis, Prognosis and Therapeutics under the Light of Science and Ethics
}

\author{
Mario Enrique Molina, Jeremías Abou Medelej, Jorgelina Zucchi and Carlos Manassero \\ Facultad de Farmacia y Bioquímica, Universidad Juan Agustín Maza, Mendoza, Argentina
}

Article history

Received: 19-07-2017

Revised: 24-07-2017

Accepted: 02-08-2017

Corresponding Author:

Mario Enrique Molina

Facultad de Farmacia y

Bioquímica, Universidad Juan

Agustín Maza, Mendoza,

Argentina

Email: mmolina@umaza.edu.ar

\section{Introduction}

Thirty-five years have elapsed since the first cases of Acquired Immuno Deficiency Syndrome (AIDS) were reported (Centers for Disease Control and Prevention CDC, 1982) and thirty-three since it was proposed that Human Immuno Deficiency Virus (HIV) is the causal agent of the disease (Montagnier et al., 1984; Haseltine and Wong-Staal, 1988). However, we are still far from finding adequate therapeutic interventions to treat these medical conditions (Gill, 1987; Kolata, 1987; Richman, et al., 1987; U.S.

\begin{abstract}
The first cases of AIDS occurred about 1981. There are not fully appropriate therapeutic interventions for treating this medical condition. People who are diagnosed HIV-positive or with AIDS suffer a poor quality of life and receive medication that produces severe adverse reactions. We have analyzed a significant number of papers published in several countries behaviors: According to the Centers for Disease Control and Prevention, in nited States, the Estimated Per-Act Probability of Acquiring HIV from an Infected Source, by Exposure Act (heterosexual) is about one in one in an investigation conducted through the University of San Francisco, California, on 442 discordant heterosexual couples no seroconversions were observed throughout the ten years the research lasted. (1985-1995). No other study of similar characteristics has been conducted ever since. Diagnostics methods: In Argentina, we employ the ELISA screening method, subsequently confirmed by a Western Blot test, but in the United Stated this last is discouraged since 2014. - Medication: Many of the drugs that are used to treat HIV are DNA chain terminators which interfere with the normal functioning and replication of normal cells. As a result, damage in the immune system and the mitochondrial DNA are reported very frequently. We ask the scientific community what we should inform the patients about all these. We urge the experts' opinion on the ethical management aspects. Since the diagnostic tests employed may result in false positives and the fact that the medication is highly toxic, we recommend that patients with HIV positive diagnosis fully re-test their condition at least once a year to minimize eventual diagnostic errors, suspending specific medications in case of discrepancies on the testing results.
\end{abstract}

Keywords: HIV, AIDS, Diagnosis, Therapy, Ethics
Department of Health and Human Services Public Health Service National Institutes of Health, 1987; Sommadossi and Carlisle, 1987; Bessen et al., 1988; Gorard et al., 1988; Helbert et al., 1988; Dubin and Braffman, 1989; Dalakas et al., 1990; Cretton et al., 1991; Heagy et al., 1991; Reisler et al., 2003; Venhoff et al., 2007; Scruggs and Naylor, 2008) and even to achieve minimum consensus on the diagnosis (Kiessling and Goulian, 1979; Duesberg, 1991; 1993; PapadopulosEleopulos et al., 1993; Turner, 1994; PapadopulosEleopulos et al., 1996; Duesberg et al., 2011) and there are still discrepancies as to the causal relationship 
between the virus and the disease (Marguart et al., 1991; Laurence et al., 1992; Afrasiabi et al., 1986; Castro et al., 1992; Bowden et al., 1991; Hishida et al., 1992; Montagnier et al., 1997), to the point that different groups advocating for the reconsideration of current theories about these conditions, their diagnosis and treatments, have been forming in the world (Baumann et al., 1995). Luc Montagnier, who won the Nobel Prize for the discovery of HIV in 2008, has made surprising statements about the low pathogenic capacity of the virus (Leung, 2009). In addition, people with an HIV-positive diagnosis are subject to disadvantageous health, economic and social conditions that severely limit their chances of development and their quality of life. The restrictions suffered by these people are due, in part, to the ignorance of certain details of the conditions by the population that causes these people to end up being discriminated against by society. Further, the medication given to these patients produces severe adverse reactions, which generate more limitations to their quality of life (Reisler et al., 2003; Venhoff et al., 2007). It is important to emphasize that, for epidemiological, age and geographic reasons, our students and their families may be included in the groups that are considered at risk for acquiring these diseases.

With this scientific investigation, which constitutes a review, we intend to study the existing theoretical framework about the etiology of AIDS and the epidemiological, biological and genetic characteristics of its supposed causal agent, HIV. Thus, this document constitutes a preliminary report of a longer and more detailed investigation to be conducted through which we will study the following aspects in a more detailed fashion: What are the epidemiological bases of retroviral infections? What are the specific conditions of HIV replication? Which are the reverse transcription mechanisms mediated by specific enzymes elicited by the activity of retroviruses and normal cells under various circumstances? What have been the results of the clinical studies of the various phases that have been performed? What is the evidence that provides electron microscopy of HIV performed in various parts of the world, to validate its morphology, function and the specific presence of retroviral proteins? Furthermore, we are in a position to critically review also the scientific and technical basis of the prospective and confirmatory diagnostic techniques, the scientific basis for the prognosis and evolution of these conditions and the basis of the current therapeutics of the disease. Some authors have gathered and analyzed impressive quantities of relevant information, yielding significant conclusions that should be considered in order to achieve a solid and integral theory about HIV and AIDS, among them, Bauer (2016) and Papadopulos-Eleopulos et al. (2017).
Our group has just started to study these matters. However, we consider it urgent to communicate some of our preliminary results to date. Some of our objectives are:

- To ensure that people affected by these conditions have access to up-to-date information, so they can make better informed decisions for their health care and achieve remarkable improvements in their quality of life

- To improve their social inclusion, based on a better understanding of the characteristics of these conditions by the community, reducing prejudice and discrimination and expanding the working horizons of the affected people

\section{Materials and Methods}

As we mentioned before, we are focused on conducting a meta-analysis and critical evaluation of the material that has already been published on the subject. By organizing, integrating and evaluating it, the authors of this review article are considering the progress of scientific research with a view to clarifying certain problems. This is how we identify relations, contradictions and inconsistencies in the scientific literature and propose steps to overcome the disadvantages encountered, according to recommendations on this type of task (UC San Diego Division of Biological Sciences, 2016).

In particular, for this report, our group has focused on analyzing scientific literature especially related to the following aspects:

- Some major aspects of epidemiology in general and especially, in our Country

- The test methods to diagnose these conditions, their sensitivity and specificity. The main findings and questions that remains unsolved in relation to these issues, the pertinent recommendations and the decision criteria to be applied by the clinical laboratories

- The theoretical chemical and pharmacological analysis of the drugs used in the treatment of these diseases, to study the expected impact of the drugs on living cells and tissues and the toxicity of these drugs in animal models and patients, with their due foundation

- The Adverse Reactions reported for the drugs used for the treatment of these conditions, both in administering one medication at a time and under various combinations of medications on the market

\section{Results}

So far we have found significant inconsistencies in the scientific literature we have consulted. Our main findings are the following. 


\section{Infection Channels and Transmission Rates by Exposure Act}

According to the US Centers for Disease Control and Prevention (CDC, 2016) the rate of transmission of HIV1 from heterosexual contact (penile-vaginal insertion) is less than one in ten thousand events from women and less than one in every two thousand events from men. So women would be at a higher risk of acquiring the virus. Epidemiologically, these risk rates are inconsistent with the fact that most people infected in the world with HIV1 are men. Moreover, in a research carried out in the University of San Francisco, which comprised 442 discordant couples -that is, one of the two members of the couples was HIV-1-positive and not the other- no new infections were observed -with and without the use of condoms- throughout the entire study that lasted 10 years (1985-1995) (Padian et al., 1997). No other study of similar characteristics has been conducted ever since. These results are also inconsistent with the transmission rates proposed by the CDC. Unfortunately, the sources of epidemiological data are not made available in our Province.

\section{Diagnostic Methods}

In Argentina, the process of testing subjects to detect the presence of HIV in the blood consists of two steps: a first step, or "screening test", using Enzyme-Linked ImmunoSorbent Assay (ELISA) and a second step using the Western Blot technique. This two-fold process is implemented because the first test has been demonstrated to yield a significant number of "false positive" results, so, it is subsequently "confirmed" by the Western Blot test. However, in the United States the use of the latter has been discouraged since 2014 (CDC, 2014). Probably because the Western Blot technique does not constitute a unequivocal diagnostic method for HIV, either. In fact, different diagnostic criteria for Western Blot have been used in different countries over the last twenty years (CDC, 1989; 2016). In Figure 1, each horizontal band represents each of the 10 major HIV proteins against which the patient's antibodies can react. The patient's serum is added to the strip and it is "revealed", that is, where a deposit of the antigen-antibody complex occurs, colored bands appear, exposing the presence of certain viral proteins. From our point of view a positive diagnosis in this phase should require the presence of all the full band profile to be present in order to diagnose a person as "HIV positive". Nevertheless, all the criteria applied in different countries of the world to confirm an HIV positive take into account the presence of only a few of these proteins and even then, there are major differences among the different criteria. Thus, a person who is diagnosed with the same laboratory kit
(GENELABS Diagnostic HIV BLOT 2.2, for example) can have been diagnosed and confirmed as HIV positive in New York and HIV negative in Australia. Or an Australian who has been diagnosed as HIV positive because of the presence of the bands p41, p32, p24 and p18 would not have been diagnosed as HIV positive in Africa, etc. (Turner, 2005). Figure 1 reproduced with permission (Papadopulos-Eleopulos et al., 2003). To cite just an example of the imprecision of the inserts of Western Blot kits in these days, this excerpt can be read in the Genelabs Diagnostic HIV Blot 2.2, published by the World Health Organization (WHO, 2016): “...Therefore, test algorithms recommended by the US CDC (2001) and WHO (2004) are yet to be updated and NAT are yet to be included as methods for resolving INDETERMINATE Western Blot results. Nevertheless, US CDC (2001) acknowledged that when in consultation with clinical and infection status among persons with an initial INDETERMINATE Western Blot Detection of antibodies to HIV-1 does not constitute a diagnosis of Acquired Immune Deficiency Syndrome (AIDS). A NEGATIVE BLOT is not a guarantee that the causative agent for AIDS is not present. Although an HIV-1 positive test result by Western Blot indicates infection with the virus, a diagnosis of AIDS can only be made clinically if a person meets the case definition of AIDS established by the Center for Disease Control (USA)".

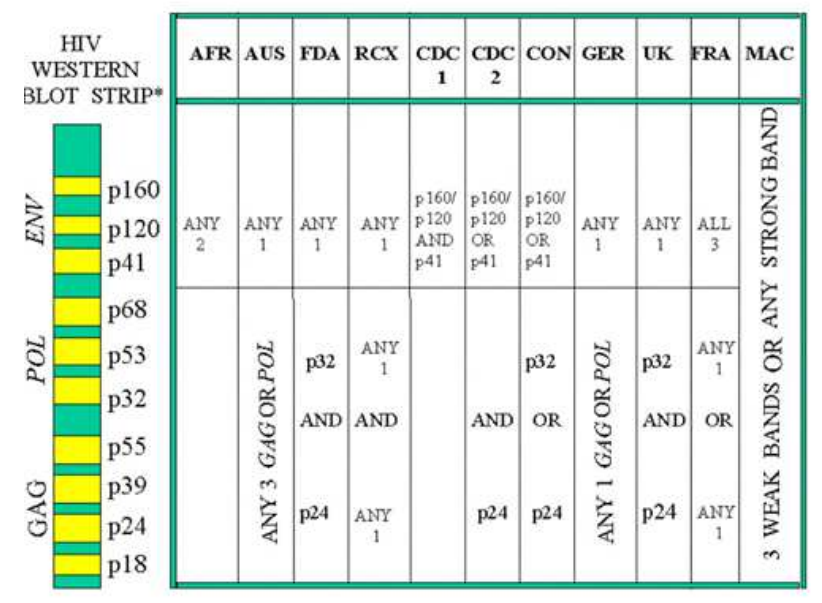

Fig. 1. Diverse diagnostics criteria for diagnosing HIV through the interpretation of the presence of specific band-proteins in Western Blot. AFR: Africa, AUS: Australia, FDA: Federal Drug Administration, RCX: Red Cross, CDC1, CDC2, CON: US Consortium for Retrovirus Serology Standardization, GER: Germany, UK: United Kingdom, FRA: France, MACS: US Multicenter AIDS Cohort Study 1983/1992. From Papadopulos-Eleopulos et al. (2003). Reproduced with permission 
<smiles></smiles><smiles>Cc1cn(C2CC3CC2OC(CO)C3N)c(=O)[nH]c1=O</smiles>

Fig. 2. The Thymidine (left) and the Zidovudine (right) molecules have very similar chemical structures. However, the "azido" (N3) radical in Zidovudine, replacing the hydroxyl radical in the same locus of Thymidine, prevents the ADN chains to form. This constitutes a mutagenic factor for all the processes involving de novo synthesis of ADN chains, especially in the cell nucleus and in mitochondria. This explains the high toxicity of these medications

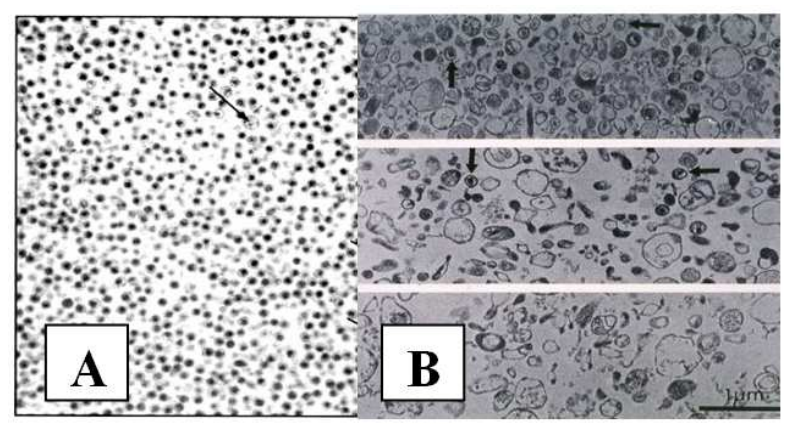

Fig. 3. A. High degree of purification of Murine Leukemia Virus. On this electron microscope image, a uniform population of virus particles is clearly recognized. They all have the same diameter and morphology. Such samples of purified retrovirus were successfully used to identify viral proteins and to extract viral RNA. The method applied to achieve this purification of a typical retrovirus is rapid, inexpensive and highly reproducible. B. Despite our best efforts, we could not find a similar degree of purification for HIV. Gluschankof et al. (1997).

\section{Specific Medication}

The specific drugs that are used to treat HIV are generally referred to as "anti-retrovirals" (ARV), but because of their molecular structure, most of them are actually nucleoside analogs that may potentially interrupt the replication of DNA strands, thus interfering with the normal functioning of the mitochondria and the healthy cells in the body. For instance, Zidovudine (Fig. 2) causes damage to red and white blood cells precursors and mitochondrial DNA at plasma concentrations 1 to 5 micromolar (Cretton et al., 1991; Dalakas et al., 1990; Dubin and Braffman, 1989; Gill, 1987; Sommadossi and Carlisle, 1987). Yet, Zidovudine is considered an "essential medicine" by the WHO (2017). Other specific medications, currently in use, have been shown to produce serious adverse reactions. It should be noted that there have been observed more Grade 4 Events (Lifethreatening Events) due to (Ganta et al., 2017; Yu et al., 2017; Fortuny et al., 2015; Sun et al., 2014; Zhang et al., 2014; Gardner et al., 2014; Liu et al., 2013; Patel et al., 2012; Hulgan and Gerschenson, 2012; Vidal et al., 2011). The medication used for treating HIV with HAART (High Activity Antiretroviral Therapy)- than those of AIDS itself (Reisler et al., 2003).

\section{Vaccines Development}

The difficulty for developing vaccines has been explained due to HIV mutations: the high coding error rate produced by the enzyme "reverse transcriptase" and the recombination of various HIV phenotypes in the DNA of infected cells (Montagnier, 2010). However, other retroviruses that respond to the same replication mechanisms do not produce mutations that prevent the development of vaccines (e.g. Murine Leukemia Virus). Likewise, a purification of more than $20 \%$ of HIV has not been reported to date, so doubts remain about the origins and specificity of the antibodies currently used in diagnosis (Leung, 2011). Figure 3 shows examples of retroviral purifications achieved. Figure 3A: de Harven (1965). Figure 3B: Gluschankof et al. (1997).

\section{Conclusion}

We have found much scientific information that differs substantially from what is commonly disseminated about the risks of HIV transmission.

Diagnostic methods are far from achieving the reliability required to establish lifelong high-risky therapies for patients. The pathogenicity of the virus is not well determined. Nor have we been able to establish how the antigens and antibodies used to make prospective or confirmatory diagnoses are obtained. Eight years after Luc Montagnier has informed us that "a normal body gets rid of HIV naturally" (Leung, 2009), we could not find any scientific publication that has elaborated this idea.

Currently, a person who is diagnosed positive for HIV is never fully re-tested, as it is assumed that this condition can never be reversed. As a result of our research and the issues we mentioned, we strongly recommend putting this assumption under scrutiny.

The main conclusion of our study is that a complete re-evaluation of all the enunciated factors should be conducted, revising the protocols and procedures for which patients are subject to. As the HIV tests are not conclusive, we suggest that persons with positive HIV diagnosis should have their condition full confirmed once a year to minimize the possibility of having been misdiagnosed. In case of controversial results, their medication should be ceased immediately, due to the potential severe adverse reactions of the specific 
drugs. We openly ask what and how these issues should be informed to the patients and to the general population and require the urgent opinion of experts on the ethical issues involved.

\section{Funding Information}

The research our group is conducting has been aproved by fundings granted by Resolución Nr. 1482. 30 Dic. 2015. Rectorado Universidad Juan Agustín Maza. Mendoza. Argentina. No conflict of interests declared.

\section{Authors' Contributions}

All the authors contributed equally to the preparation of this paper.

\section{Ethics}

There are no ethical issues relating to the review of published scientific papers.

\section{References}

Afrasiabi, R., R.T. Mitsuyasu, P. Nishanian, K. Schwartz and J.L. Fahey, 1986. Characterization of a distinct subgroup of high-risk persons with Kaposi's sarcoma and good prognosis who present with normal T4 cell number and T4:T8 ratio and negative HTLV-III/LAV serologic test results. Am. J. Med., 81: 969-973. DOI: 10.1016/0002-9343(86)90389-x

Bauer, H., 2016. The case against HIV. http://thecaseagainsthiv.net/

Baumann, E., T. Bethell, H. Bialy, P.H. Duesberg and C. Farber et al., 1995. AIDS proposal. Lett. Sci., 267: 945-946. DOI: 10.1126/science.7863334

Bessen, L., B, G. J., Louie, E., Seitzman, E. and Weinberg, H. 1988. Severe polymyositis-like syndrome associated with zidovudine therapy of AIDS and ARC. New England J. Med., 318: 708-708. DOI: $10.1056 /$ nejm198803173181113

Bowden, F.J., S. Sonza, S.M., Crowe, D.A. McPhee and N.J., Deacon et al., 1991. Antibodies to Gp41 and Nef in otherwise HIV-negative homosexual man with kaposi's sarcoma. Lancet, 337: 1313-1314. DOI: 10.1016/0140-6736(91)92982-8

Castro, A., J. Pedreira, V. Soriano, I. Hewlett and B. Jhosi et al., 1992. Kaposi's sarcoma and disseminated tuberculosis in HIV-negative individuals. Lancet, 339: 868.

DOI: 10.1016/0140-6736(92)90308-p

CDC, 1982. MMWR. A Cluster of Kaposi's Sarcoma and Pneumocystis Carinii Pneumonia among Homosexual Male Residents of Los Angeles and Range Counties, California. https://www.cdc.gov/mmwr/preview/mmwrhtml/00 001114.htm
CDC, 1989. MMWR. Obtained from interpretation and use of the western blot assay for serodiagnosis of human immunodeficiency virus type 1 infections. https://www.cdc.gov/mmwr/preview/mmwrhtml/0000 1431.htm

CDC, 2014. Laboratory testing for the diagnosis of HIV infection. Updated Recommendations. http://www.cdc.gov/hiv/pdf/hivtestingalgorithmreco mmendation-final.pdf

CDC, 2016. Retrieved from "Estimated Per-Act Probability of Acquiring HIV from an Infected Source," by Exposure Act. http://www.cdc.gov/hiv/risk/estimates/riskbehavi ors.html

Cretton, E., M. Xie, R. Bevan, N. Goudgaon and R. Schinazi et al., 1991. Catabolism of 3'-azido-3'deoxythymidine in hepatocytes and liver microsomes, with evidence of formation of $3^{\prime}$ amino-3'-deoxythymidine, a highly toxic catabolite for human bone marrow cells. Molecular Pharmacol., 39: 258-266. http://molpharm.aspetjournals.org/content/39/2/25 8.long

Dalakas, M., I. Illa, G. Pezeshkpour, J. Laukaitis, B. Cohen and J. Griffin, 1990. Mitochondrial myopathy caused by long-term zidovudine therapy. New England J. Med., 322: 1098-105. DOI: $10.1056 /$ nejm199010043231414

de Harven, E., 1965. Viremia in Friend murine leukemia: The electron microscope approach of the problem. Pathologie-Biologie, 13: 25-134.

Dubin, G. and M. Braffman, 1989. Zidoyudine-Induced Hepatotoxicity. Annals Internal Med., 110: 85-86. DOI: 10.7326/0003-4819-110-1-85

Duesberg, P., 1991. AIDS epidemiology: Inconsistencies with human immunodeficiency virus and with infectious disease. Proc. National Academy Sci., 88: 1575-1579. DOI: 10.1073/pnas.88.4.1575

Duesberg, P., 1993. The enigma of slow viruses. Lancet, 342: $\quad 720$. http://www.duesberg.com/papers/the\%20enigma.pdf

Duesberg, P., D. Mandrioli, A. Mc Cormack, J. Nicholson and D. Rasnick et al., 2011. AIDS sice 1984: no evidence for a new, viral epidemic-not even in Africa. Italian J. Anatomy Embryology, 116: 73-92.

Fortuny, C., A. Deyà-Martínez, E. Chiappini, L. Galli and M. De Martino et al., 2015. Metabolic and renal adverse effects of antiretroviral therapy in HIVinfected children and adolescents. Pediatric Infectious Disease J., 34: S36-S43. DOI: $10.1097 /$ INF.0000000000000663

Ganta, K.K., A. Mandal and B. Chaubey, 2017. Depolarization of mitochondrial membrane potential is the initial event in non-nucleoside reverse transcriptase inhibitor efavirenz induced cytotoxicity. Cell Biol. Toxicol., 33: 69-82. DOI: 10.1007/s10565-016-9362-9 
Gardner, K., P. Hall, P. Chinnery and B. Payne, 2014. HIV treatment and associated mitochondrial pathology: Review of 25 years of in vitro, animal and human studies. Toxicol Pathol., 42: 811-22. DOI: $10.1177 / 0192623313503519$

Gill, P., 1987. Azidothymidine associated with bone marrow failure in the Acquired Immunodeficiency Syndrome (AIDS). Annals Internal Med., 107: 502. DOI: 10.7326/0003-4819-107-4-502

Gluschankof, P., I. Mondor, H.R. Gelderblom and Q.J. Sattentau, 1997. Cell membrane vesicles are a major contaminant of gradient-enriched human immunodeficiency virus type-1 preparations. Virology, 230: 125-133. DOI: $10.1006 /$ viro.1997.8453

Gorard, D., K. Henry, R. Guiloff, P. Panegyres and N. Tan et al., 1988. Necrotising myopathy and zidovudine. Lancet, 331: 1050-1051. DOI: $10.1016 / \mathrm{s} 0140-6736(88) 91865-\mathrm{x}$

Haseltine, W. and F. Wong-Staal, 1988. The molecular biology of the AIDS virus. Scientific Am., 259: 52-62.

Heagy, W., C. Crumpacker, P.A. Lopez and R.W. Finberg, 1991. Inhibition of immune functions by antiviral drugs. J. Clinical Investigation, 6: 1916-924. DOI: $10.1172 /$ jci1 15217

Helbert, M., T. Fletcher, B. Pedle, J. Harris and A. Pinching, 1988. Zidovudine-associated myopathy. Lancet, 332: 689-690.

DOI: $10.1016 / \mathrm{s} 0140-6736(88) 90506-5$

Hishida, O., E. Ido, T. Igarashi, M. Hayami and M. Miyazaki et al., 1992. Clinically diagnosed AIDS cases without evident association with HIV type I and II infections in Ghana. Lancet, 340: 971-72. DOI: 10.1016/0140-6736(92)92856-b

Hulgan, T. and M. Gerschenson, 2012. HIV and mitochondria: more than just drug toxicity. J. Infect. Dis., 205: 1769-1771. DOI: 10.1093/infdis/jis105

Kiessling, A. and M. Goulian, 1979. Detection of reverse transcriptase activity in human cells. Cancer Res., 39: 2062-2069. http://cancerres.aacrjournals.org/content/canres/39/6 _Part_1/2062.full.pdf

Kolata, G., 1987. Marrow suppression hampers AZT use in AIDS victims. Science, 235: 1463.

DOI: $10.1126 /$ science. 3823897

Laurence, J., E. Schattner, F. Siegal, I. Gelman and S. Morse, 1992. Acquired immunodeficiency without evidence of infection with human immunodeficiency virus types 1 and 2. Lancet, 340: 273-74. DOI: 10.1016/0140-6736(92)92359-n

Leung, B., 2009. Nobel laureate montagnier: HIV can be cleared naturally - house of numbers. Obtained from Nobel Laureate Montagnier: HIV Can Be Cleared Naturally-House of Numbers. https://www.youtube.com/watch?v=tKyIBYKoT20 \&list=PL9996C6698A0BE6DA\&index $=16$
Leung, B., 2011. Hans Gelderblom Extended Interview min. 37.48 Obtained from House of Numbers. https://www.youtube.com/watch?v=pKEZxdRWXXw

Liu, K., Y. Sun, D. Liu, J. Yin and L. Qiao et al., 2013. Mitochondrial toxicity studied with the PBMC of children from the Chinese national pediatric highly active antiretroviral therapy cohort. PLoS One. DOI: 10.1371/journal.pone.0057223

Marguart, E., R. Engst and G. Oehlschlaegel, 1991. An 8year history of Kaposi's sarcoma in an HIV-negative bisexual man. AIDS, 5: 346-348. https:/www.ncbi.nlm.nih.gov/pubmed/?term=An+8year+history+of+Kaposi $\% 27 \mathrm{~s}+$ sarcoma $+\mathrm{in}+\mathrm{an}+\mathrm{HI}$ $\mathrm{V}$-negative+bisexual

Montagnier, L., 2010. 25 years after HIV discovery: Prospects for cure and vaccine. Virology, 397: 248254. DOI: 10.1016/j.virol.2009.10.045

Montagnier, L., C. Brenner, S. Chamaret, D. Guetard and A. Blanchard et al., 1997. Human immunodeficiency virus infection and AIDS in a person with negative serology. J. Infectious Dis., 175: 955-99. DOI: 10.1086/513999

Montagnier, L., J. Chermann, F. Barre-Sinoussi, S. Chamaret and J. Gruest et al., 1984. A New Human T-lymphotropic Retrovirus: Characterization and Possible Role in Lymphadenopathy and Acquired Immune Deficiency Syndromes. In: Human T-cell Leukemia/Lymphoma Virus; The Family of Human T-Lymphotropic Retroviruses: Their Role in Malignancies and Association with AIDS, R. Gallo, M. Essex and L. Gross, (Eds.), New York: Cold Spring Harbor, pp: 363-379.

Padian, N., S. Shiboski, S. Glass and E. Vittinghoff, 1997. Heterosexual transmission of Human Immunodeficiency Virus (HIV) in northern California: Results from a ten-year study. Am. J. Epidemiology, 146: 350-357.

DOI: 10.1093/oxfordjournals.aje.a009276

Papadopulos-Eleopulos, E., 2017. HIV- a virus like no other. The Perth Group. http://www.theperthgroup.com/HIV/TPGVirusLike NoOther.pdf

Papadopulos-Eleopulos, E., V. Turner and J. Papadimitriou, 1993. Is a positive western blot proof of HIV infection? Nature Biotechnology, 11: 696-707. DOI: $10.1038 /$ nbt0693-696

Papadopulos-Eleopulos, E., V. Turner, J. Papadimitriou, D. Causer and B. Hedland-Thomas et al., 1996. A critical analysis of the HIV-4-cell-AIDS hypothesis. AIDS: Virus- or Drug Induced? Contemporary Issues in Genetics and Evolution. DOI: 10.1007/978-94-009-1651-7_1 
Papadopulos-Eleopulos, E., V. Turner, J. Papadimitriou, D. Causer and A. Helman, 2003. Distinguishing between true and official HIV infection.

Patel, K., R. Van Dyke, M. Mittleman, S. Colan and J. Oleske et al., 2012. The impact of HAART on cardiomyopathy among children and adolescents perinatally infected with HIV-1. AIDS, 26: 2027-37. DOI: 10.1097/QAD.0b013e3283578bfa

Reisler, R., W. Cong Han, E. Burman, E. Tedaldi and J. Neaton, 2003. Grade 4 events are as important as AIDS events in the era of HAART. J. Acquired Immune Deficiency Syndromes, 34: 379-86. DOI: $10.1097 / 00126334-200312010-00004$

Richman, D., M. Fischl, M. Grieco, M. Gottlieb and P. Volberding et al., 1987. The Toxicity of Azidothymidine (AZT) in the treatment of patients with AIDS and AIDS-related complex. A doubleblind, placebo-controlled trial. New England J. Med., 317: 192-197.

DOI: $10.1056 /$ NEJM198707233170402

Scruggs, E. and A. Dirks Naylor, 2008. Mechanisms of zidovudine-induced mitochondrial toxicity and myopathy. Pharmacology, 82: 83-88.

DOI: $10.1159 / 000134943$

Sommadossi, J. and R. Carlisle, 1987. Toxicity of 3'azido-3'-deoxythymidine and 9- (1,3-dihydroxy-2propoxymethyl) guanine for normal human hematopoietic progenitor cells in vitro. Antimicrobial Agents Chemotherapy31, 3: 452-54. DOI: 10.1128 /aac.31.3.452

Sun, R., S. Eriksson and L. Wang, 2014. Downregulation of mitochondrial thymidine kinase 2 and deoxyguanosine kinase by didanosine: Implication for mitochondrial toxicities of anti-HIV nucleoside analogs. Biochemical Biophysical Research Communications, 450: 1021-6. DOI: $10.1016 /$ j.bbrc.2014.06.098

Turner, V., 1994. HIV western blot test (letter). Medical Journal Aus., 160: 807-808. https://www.ncbi.nlm.nih.gov/pubmed/8208208

Turner, V., 2005. Detection of acute HIV infections. New England J. Med., 631-632.

U.S. Department of Health and Human Services Public Health Service National Institutes of Health, 1987. Technical Report on the Toxicology and carcinogenesis studies of AZT (CAS No. 30516-87-1) and AZT / [alpha] -interferon A / D in B6C3F1 mice (gavage studies). https://ntp.niehs.nih.gov/ntp/htdocs/lt_rpts/tr469.pdf
UC San Diego Division of Biological Sciences, 2016. Saltman. Retrieved from what is a Scientific Review Paper. https://sqonline.ucsd.edu/wpcontent/uploads/2015/02/Review_Paper_Guidelines final.pdf

Venhoff, N., B. Setzer, K. Melkaoui and U. Walker, 2007. Mitochondrial toxicity of tenofovir, emtricitabine and abacavir alone and in combination with additional nucleoside reverse transcriptase inhibitors. Antiviral Therapy, 12: 1075-85.

Vidal, F., P. Domingo, C. Viladés, J. Peraire and M. Arnedo et al., 2011. Pharmacogenetics of the lipodystrophy syndrome associated with HIV infection and combination antiretroviral therapy. Expert Opinion Drug Metabolism Toxicology, 7: 1365-82. DOI: 10.1517/17425255.2011.621941

WHO, 2016. Retrieved from WHO. Prequalification of in vitro diagnostics programme public report product: MP diagnostics HIV Blot 2.2 Number: PQDx 0198071-00.

http://www.who.int/diagnostics_laboratory/evaluation s/160404_final_public_report_0198_071_00_v2.pdf

WHO, 2017. Retrieved from WHO. Model Lists of Essential

Medicines. http://www.who.int/medicines/publications/essential medicines/EML_2017_EC21_Unedited_Full_Repor t.pdf?ua=1

Yu, F., Y. Hao, H. Zhao, J. Xiao and N. Han et al., 2017. Distinct Mitochondrial Disturbance in $\mathrm{CD} 4+\mathrm{T}$ and CD8+T Cells From HIV-Infected Patients. J. Acquired Immune Deficiency Syndrome, 74: 206-212. DOI: 10.1097/QAI.0000000000001175

Zhang, Y., F. Song, Z. Gao, W. Ding and L. Qiao et al., 2014. Long-term exposure of mice to nucleoside analogues disrupts mitochondrial DNA maintenance in cortical neurons. PLoS One, 9: e85637. DOI: $10.1371 /$ journal.pone. 0085637 